\title{
O PAPEL DA COMUNICAÇÃO NA GESTÃO POR PROJETOS: UM ESTUDO DE CASO EM EMPRESA PARAESTATAL
}

\section{THE COMMUNICATION ROLE ON PORTFOLIO MANAGEMENT: A CASE STUDY AT PARAGOVERNMENTAL ORGANISATION}

\author{
Jorge Luciano Gil Kolotelo; ${ }^{1}$ Hélio Gomes Carvalho ${ }^{2}$ \\ ${ }^{1}$ Federal Technological University of Paraná - UTFPR - Ponta Grossa - Brasil \\ kolotelo@uol.com.br \\ ${ }^{2}$ Federal Technological University of Paraná - UTFPR - Ponta Grossa - Brasil \\ helio@utfpr.edu.br
}

\begin{abstract}
Resumo
A velocidade de transformação na qual o mundo tem passado trouxe um novo paradigma organizacional conduzido e pressionado pelos vetores social, econômico, ambiental e tecnológico, imprimindo um caráter inovativo e dinâmico na capacidade de formulação da estratégia e na conexão inteligente e sincronizada das atividades fim. Este processo de reorganização, imposto pela era da economia do conhecimento, reforça a necessidade de novos modelos de gestão e de projetos ajustados com maior eficácia de forma a cumprir com os objetivos estratégicos. Executar o planejamento estratégico, seus projetos associados e conduzir pessoas, deve ser proporcionado por um processo de comunicação sistematizado, articulado e coerente. O objetivo deste trabalho foi avaliar os processos de comunicação entre objetivos estratégicos e os projetos em uma organização que trabalha por projetos. Escolheu-se uma empresa privada de direito público onde foram analisadas as respostas aos questionários enviados a colaboradores ligados a projetos a partir do contexto anterior e à luz da literatura pesquisada. O estudo de caso, valendo-se da metodologia aplicada que se verificou eficiente, confirmou a hipótese apresentada e o resultado do problema de pesquisa levantou as disfunções da comunicação que podem ser utilizadas como fonte para um trabalho de melhoria.
\end{abstract}

Palavras-chave: Comunicação; Gerenciamento por Projetos; Gestão de Portifolios; Paraestatal.

\section{Introdução}

A atual transformação que o mundo vem enfrentando, tanto do ponto de vista sócioeconômico-ambiental quanto tecnológico, vem impactando a forma como empresas têm se posicionado no mercado para se adequar e ajustar às mudanças. Isto tem levado empresas, organizações e instituições a inovações em produtos, serviços e processos para alcançar a competitividade, crescimento e sobrevivência. "A habilidade de aprender mais rápido do que seus concorrentes pode ser a única vantagem competitiva sustentável.” (GEUS, apud MARTIN, 1996, p. 22). 
Entretanto, estes ajustes não têm sido satisfatórios e segundo Pimenta (2004) a perda de competitividade no mercado globalizado, conflitos internos, perda de tempo e qualidade de vida estão relacionados aos problemas de comunicação com os quais o gerente de projetos deve ficar atento. E é neste contexto que se pretende trabalhar com o papel da comunicação na gestão de projetos.

À luz do que foi exposto tem-se na comunicação o principal elemento para o alinhamento destes projetos e atividades aos objetivos estratégicos. Esta hipótese aponta para a seguinte pergunta de pesquisa: "Como melhorar a comunicação das informações sobre os projetos da organização?" que atue em gerenciamento de projetos.

\section{Contextualização}

Considerando que estamos tratando da comunicação entre as atividades dos projetos que atendam a direção estratégica definida a partir de um cenário econômico os temas levantados em literatura mais influenciam e impactam estão assim resumidos:

Segundo Porter (1999, p.29), referindo-se às forças que governam a competição, as mudanças estratégicas de negócios e padrões de gerenciamento são feitas para enfrentar os novos desafios da competição de mercados e as inovações tecnológicas. Além disto, e do ponto de vista da capacidade produtiva de uma sociedade, os principais elementos condicionantes são - além dos recursos naturais, do número de pessoas e do contexto sócio-econômico - o conhecimento e habilidade da força de trabalho, do estoque de capital disponível no processo e eficiência destes instrumentos, ou seja, o nível de conhecimento tecnológico aplicado (BASTOS; SILVA, 1995, p. 114).

Após a Segunda Guerra Mundial o modelo japonês retoma a economia e aprimora a produção com a filosofia do Kaizem ou sistema Toyota de produção e sob esta influência Burns e Stalker mapeiam os modelos Mecanicista e Orgânico.

Diante da evolução e das necessidades ao longo do tempo um novo estilo administrativo e gerencial é conduzido pela reinvenção do trabalho e pela forma de administrar a empresa através de novas abordagens com o uso da experimentação e o empowerment de funcionários, equipes e parcerias conforme resumido na tabela 1 .

Tabela 1 - resumo das mudanças no trabalho

\begin{tabular}{|c|c|}
\hline ESTILO ANTIGO & ESTILO NOVO \\
\hline Divisão da mão de obra & Empowerment dos funcionários \\
\hline Divisão e simplificação do trabalho & $\begin{array}{c}\text { Trabalho enriquecido funcionários engajados em várias } \\
\text { tarefas, expandindo seu conhecimento }\end{array}$ \\
\hline Operários de custo mais baixo & Operários de valor mais alto \\
\hline
\end{tabular}




\begin{tabular}{|c|c|}
\hline ESTILO ANTIGO & ESTILO NOVO \\
\hline Taylorismo & Kaizen \\
\hline $\begin{array}{c}\text { Não se considera que os operários exerçam um efeito } \\
\text { importante sobre a qualidade }\end{array}$ & Qualidade considerada tarefa de todos \\
\hline Operários sem participação no processo de trabalho & $\begin{array}{l}\text { Funcionários participando na elaboração de rotinas de } \\
\text { trabalho }\end{array}$ \\
\hline Gerência dá as ordens; operários obedecem sem discutir & Gerência participativa, equipes autogerenciadas \\
\hline Um modo mais eficaz de trabalho definido pela gerência & $\begin{array}{c}\text { Todos os funcionários aprendem continuamente e } \\
\text { contribuem com o aprendizado da empresa }\end{array}$ \\
\hline Experimentação realizada pelos cientistas & $\begin{array}{c}\text { Experimentação realizada por várias equipes de } \\
\text { funcionários }\end{array}$ \\
\hline $\begin{array}{l}\text { Custo de mão-de-obra minimizado por etapas de trabalho } \\
\text { padronizado }\end{array}$ & $\begin{array}{l}\text { Treinamento e iniciativa de cada funcionário visando } \\
\text { garantir a maior contribuição possível }\end{array}$ \\
\hline A maioria das tarefas simples & Uso sofisticado de ferramentas criativas e computadores \\
\hline Trabalho desumano & Trabalho proporciona respeito e realização pessoal \\
\hline $\begin{array}{c}\text { Não se espera (ou não se permite) que maioria dos } \\
\text { operários pense }\end{array}$ & Espera-se que todos os operários usem sua criatividade \\
\hline Gerência hierárquica & Organizações horizontais, equipes inter-funcionais \\
\hline Canais formais de informação & Livre acesso à informação \\
\hline Feudos funcionais & Organização desfronteirizada \\
\hline
\end{tabular}

Fonte: MARTIN, 1996 (p. 48)

Entretanto, segundo Siqueira (1998, in Dinsmore et al., p.29), enquanto que na iniciativa privada a inovação e a economia impulsionam as mudanças pela competitividade na administração pública encontra-se limitadores humanos e financeiros regidos pelos vetores: geração de poupança própria; participação da população; captação de recursos; venda do município; parcerias intermunicipais; desenvolvimento econômico social; racionalização da legislação; e reengenharia do governo.

Por outro lado, entidades Paraestatais são pessoas jurídicas de Direito Privado que têm autorizadas as suas instituições, como patrimônio público ou misto, a realização de atividades, obras ou serviços de interesse coletivo e social, sob normas e controle do Estado (DL-57.375/65 e 494/62). As paraestatais, portanto, seriam apenas os serviços sociais autônomos (Exemplo, SENAC, SESC, SESI, SENAI, etc.).

As características operacionais destas entidades são:

a) ambigüidade entre entregar produtos demandados pelos clientes com a velocidade que o mercado imprime e a lentidão que tem origem nas regulações, para a consecução dos objetivos;

b) inovação e volume de serviços nas entregas contratadas;

c) e, apesar da linha de produto ser basicamente estática (a exemplo do SESI e SENAI Educação, Lazer, Tecnologia, etc.), a composição final dos produtos é moldada conforme os requisitos do cliente e, desta forma, passam por um mix de opções e customizações com características singulares de escopo, prazo, recursos, custos e qualidade. 
Este conjunto de características é suficiente para concluir se sobre: a complexidade inerente a esta entidade e a dificuldade de se estabelecer processos com clareza na linha de produção (exceto nas áreas administrativas) o que leva para a definição de projetos.

As diferenças entre os dois tipos de iniciativas: Público $x$ Privado estão na tabela 2.

Tabela 2 - Diferenças entre setor privado e público

\begin{tabular}{|c|c|}
\hline ÁREA PRIVADA & ÁREA PÚBLICA \\
\hline Tudo pode, exceto onde a lei proíbe & Tudo é proibido, exceto onde a lei permite \\
\hline Salários compatíveis ao mercado & Salários inadequados \\
\hline Maior disponibilidade de pessoal qualificado & Dificuldade de obtenção de pessoal qualificado \\
\hline Possível implantar política de incentivo & Difícil implantar política de incentivo \\
\hline Estrutura de poder formal próxima do informal & Maior incidência de disfunção \\
\hline Baixa incidência de disfunção & Evidência no desacordo com os objetivos \\
\hline Organização voltada para os objetivos & Presença marcante da burocracia \\
\hline Prioridade e objetivos, estabelecidos pela diretoria & Prioridades e objetivos negociados com a sociedade. \\
\hline Pouca burocracia & A cobrança da sociedade é de caráter mais subjetivo \\
\hline Alta administração sofre cobrança permanente quanto a & Risco quanto à quebra da continuidade administrativa \\
\hline objetivos e metas a serem atingidos & Freqüentemente ocorrem paralisações de programas e \\
pontinuidade administrativa mais permanente & Maior dispersão quanto à tomada de decisão \\
\hline $\begin{array}{c}\text { Pouco freqüente a paralisação de programas e projetos por } \\
\text { falta de recursos }\end{array}$ & Pouco uso das ferramentas de planejamento e controle \\
\hline Decisão dos objetivos é centrada em poucos órgãos & Conceito de qualidade ainda incipiente \\
\hline Muito uso de ferramentas de planejamento e controle & Baixa inserção na realidade da competição \\
\hline Voltado para qualidade & \\
\hline Impulsionada pela competitividade &
\end{tabular}

Fonte: DINSMORE et al., 1998, p.42 (resumo adaptado)

Segundo Karlof (1999) a história nos mostra que o desenvolvimento na área de negócios resume a influência de uma abordagem sistêmica envolvendo não só negócio, mas também recursos, conhecimento, pessoas e criação de valor, confirmada por Martin (MARTIN, 1996).

A própria estratégia, arte de coordenar a ação das forças militares, políticas, econômicas e morais implicadas na condução de um conflito ou na preparação da defesa de uma nação ou comunidade, tomou várias conotações ao longo do tempo conforme tabela 3.

Tabela 3 - Autores e abordagens estratégicas

\begin{tabular}{|c|l|}
\hline AUTOR & \multicolumn{1}{|c|}{ PALAVRAS-CHAVE } \\
\hline Mintzberg & Futuro, decisão, resultados, programação \\
\hline Ansoff & Negócio atual, tendências, decisão, concorrência, produtos e serviços \\
\hline Pascale & Seleção de oportunidades, produtos e serviços, investimento de recursos, objetivos \\
\hline Chandler & Metas e objetivos de longo prazo, custos de ação, alocação de recursos \\
\hline Hampton & Vantagens em relação aos desafios do ambiente, adaptação da empresa ao ambiente \\
\hline Porter & Vantagem competitiva, atividades de valor, poder de negociação, ameaças \\
\hline
\end{tabular}

Fonte: MAXIMIANO, 2000, p. 393 (adaptado) 
A estratégia fundamenta-se no estabelecimento de objetivos e missões necessárias à sobrevivência de uma empresa e Mintzberg (2000) referencia estratégia como uma direção, um guia ou curso de ação para o futuro, um, caminho para ir daqui até ali.

Galbraith (1995, p. 8) mostra que as diferentes estratégias levam aos diferentes tipos de estruturas organizacionais e que o alcance da eficiência e da eficácia operacional depende das atividades e suas relações ambientais, do modelo organizacional quanto às concepções mecanicista e orgânica e da confirmação ou re-concepção do modelo escolhido.

Estas formas variadas de corporação resultam das mudanças que além da estrutura organizacional do grau de centralização, do tamanho e função da cúpula, da estrutura funcional, do tipo de controle, sistema de remuneração entre outras a empresa transmite por toda sua estrutura seu modu operandi comunicando sua estratégia a todos os seus níveis e aos Clientes. Neste caso uma forte interdependência entre Estratégia x Estrutura aparece no alinhamento da Dimensão Organizacional e seus vários componentes que estabelecem uma relação entre:

a) Volume de diversificação na carteira ou portfolio dos negócios com que a empresa opera;

b) Tipo e volume de valor que a empresa agrega aos seus negócios. Esta relação pode ser vista na figura 1.

Figura 1 Relação de efetividade e produtividade

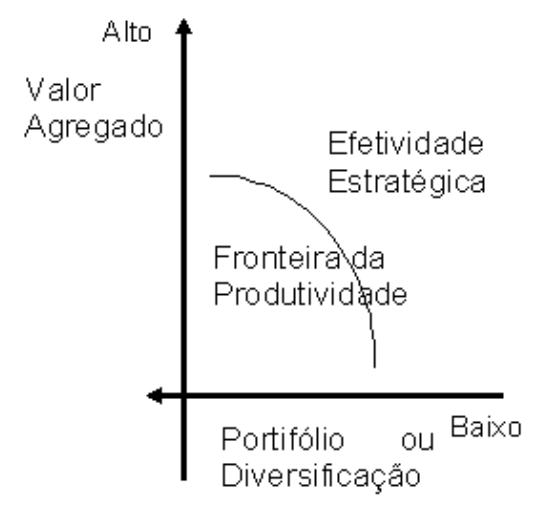

Communicationis do latim é a ação de partilhar, comunicar, de dividir. Enraizada na dimensão da natureza humana e no seu comportamento dentro da estrutura social é um processo de troca de informação que utiliza símbolos ou protocolos de forma a interagir ou passar informação, portanto dentro de uma organização tem a função de transmitir ordens, idéias, políticas de ação, etc..

A comunicação pode ocorrer nas formas oral, gráfica, estática ou dinâmica, utilizando-se de meios como: papel, eletrônico, verbal, corporal, em situações de reuniões, seminários, encontros, conferência, discursos. 
Para Hohlfeldt et al (2001, apud Pimenta, 2004), comunicação é o processo de compartilhar um mesmo objeto de consciência, distinguindo informação da comunicação. Mas segundo Vasconcellos e Hemsley (2003), os problemas da comunicação como uma das principais fraquezas das estruturas de empresas tradicionais, são mais graves à medida que o nível hierárquico aumenta.

A comunicação eficaz, segundo Argyris (1999), passa pela necessidade de sintetizar a comunicação fragmentada promovendo a cultura informacional relevante e fluída e que tem como obstáculos:

a) Padrões disfuncionais de comportamento;

b) Falta de visão e liderança organizacional;

c) Barreiras estruturais e geográficas;

d) Barreiras interculturais;

e) Excesso de dados.

Comparando as abordagens anteriores verifica-se que a comunicação permeia toda a estrutura da empresa desde a realização das operações, atividades e tomadas de decisão até sua estratégia, sendo que o sucesso depende de que as informações sejam dadas de forma compreensível e que, os princípios norteadores da boa comunicação sejam seguidos: simplificar; utilizar-se de metáforas e exemplos; utilizar de veículos de comunicação; repetir, repetir, repetir; liderança pelo exemplo; ouvir e ser ouvido; segundo Boyett \& Boyett (1999, cap. 2) e que as barreiras colocadas por Argyris (1999) sejam resolvidas. Em resposta a esta proposição criou-se a tabela 4.

Tabela 4 - Disfunções da comunicação e causa principal

\begin{tabular}{|c|c|c|}
\hline Tópico & Item discutido & Causa principal \\
\hline \multirow{2}{*}{$\begin{array}{l}\text { Comunicação } \\
\text { Disfuncional }\end{array}$} & Confiar na liderança & Barreiras à franqueza e pela hierarquia \\
\hline & Incompetência hábil & Institucionalização de padrões defensivos \\
\hline \multirow{3}{*}{$\begin{array}{l}\text { Aprendendo } \\
\text { a Ouvir }\end{array}$} & $\begin{array}{l}\text { Barreiras para a } \\
\text { comunicação }\end{array}$ & Incapacidade de ouvir de forma inteligente, compreensiva e hábil; \\
\hline & Seleção de Pessoas & Despreparo para conduzir entrevista produtiva \\
\hline & $\begin{array}{c}\text { Enfrentando a } \\
\text { imprensa } \\
\end{array}$ & Desconhecimento da regra do jogo da mídia impressa e televisiva \\
\hline \multirow{3}{*}{$\begin{array}{l}\text { Gerenciando } \\
\text { Reuniões }\end{array}$} & Condução equivocada & Falta de objetivo \\
\hline & $\begin{array}{l}\text { Conflitos devido ao } \\
\text { planejamento }\end{array}$ & Falta de preparo na identificação de recursos \\
\hline & Criatividade e poder & Falta de espírito colaborativo, respostas condicionadas. \\
\hline \multirow{3}{*}{$\begin{array}{l}\text { Redação } \\
\text { Segura }\end{array}$} & Estilo & Falta de padrão, excesso de formalidade, inflexibilidade \\
\hline & Clareza & $\begin{array}{l}\text { Ausência de impessoalidade, excesso de verbosidade, incoerência } \\
\text { política }\end{array}$ \\
\hline & Planos de negócios & Falta de preparo, de avaliação prévia e conhecimento do receptor. \\
\hline \multirow{3}{*}{$\begin{array}{l}\text { Mensagens } \\
\text { reveladas em } \\
\text { canais } \\
\text { ocultos }\end{array}$} & Rede informacional & Despreparo da liderança pra com o trato à comunicação informal \\
\hline & $\begin{array}{l}\text { Mensagens ocultas dos } \\
\text { gerentes }\end{array}$ & Inconsistência entre a linguagem escrita, falada e praticada. \\
\hline & $\begin{array}{l}\text { Mensagens ocultas na } \\
\text { rede de computadores }\end{array}$ & Volume e qualidade da informação. \\
\hline
\end{tabular}




\begin{tabular}{|c|c|c|}
\hline Tópico & Item discutido & Causa principal \\
\hline $\begin{array}{c}\text { Articulando } \\
\text { Metas e } \\
\text { Cultura }\end{array}$ & $\begin{array}{c}\text { Simplicidade e } \\
\text { autoconfiança }\end{array}$ & Liderança incapaz de articular cultura que oriente a visão da empresa \\
\cline { 2 - 3 } & Armadilha da visão & Falta de compreensão entre a visão e capacidade da empresa. \\
\hline
\end{tabular}

Nesta sofisticada e complexa era de organização em rede, alianças globais e compartilhamento de informação instantânea, organizações dependem ainda mais da integridade individual. A eficiência dependerá da confiança e credibilidade entre pessoas (GALBRAITH, 1995, p.35, 237).

Apesar dos benefícios do GP (Gerenciamento de Projetos) este ainda não é totalmente compreendido e o grande problema apontado por Cleland (2002, cap. 2) são: não ter o trabalho alinhado aos objetivos estratégicos; dificuldade em fazer com que o fluxo de informações do topo chegue à base.

Em contrapartida, estes benefícios trazem à tona outras dificuldades associadas à comunicação, como: maiores complexidade e amplitude dos projetos, pela diversidade de tecnologias, especificidades, pelas regiões geográficas e culturas impostas pelo ambiente de competitividade e inovação tecnológica.

A Estrutura por Projeto possibilita à empresa compartilhar recursos, infra-estrutura e processos administrativos, aumentando a flexibilidade, gerando dinamismo e descentralizando responsabilidades. Entretanto, para a execução de múltiplos projetos exige-se controle de programas com certas especificidades como:

a) gerenciamento de programa;

b) comitê diretivo;

c) controle centralizado dos projetos;

d) escritório de apoio a projetos; e

e) equipe de gerentes de projetos.

Aumentando-se o número de projetos na empresa, aumenta-se a complexidade administrativa e a análise desta carteira de projetos que como objetivo assegurar a melhoria da qualidade do próprio Gerenciamento de Projetos, na medida em que cada projeto, individualmente, contribui compartilhando experiências, métodos, ferramentas e, ainda, redirecionar eventuais desvios das estratégias.

A Estrutura por projetos possibilita compartilhar recursos, infra-estrutura e processos administrativos possibilitando a flexibilidade, gerando dinamismo e descentralizando responsabilidades. 
O conceito para gerenciamento de Projetos vai além das simples habilidades de planejar, executar, conduzir, controlar e finalizar um projeto porque pressupõe um gerente com responsabilidade para conduzi-lo.

A relação entre os projetos que garantam atingir os objetivos estratégicos da empresa não deve ser confundido com o gerenciamento que trata dos objetivos estratégicos específicos do projeto.

Após selecionados, as empresas precisam se assegurar que estes projetos serão executados, avaliados constantemente e decidir sobre sua continuidade ao longo de seu ciclo de vida e, para que obtenham sucesso, precisam de basicamente das medidas: escopo, custos, recursos e tempo.

O papel da comunicação na construção e implementação das estratégias nas empresas é importante para a lide dos projetos. As fontes de intercâmbio e de informação com sistemas informatizados e compartilhados devem facilitar a criação, coleta e disponibilização de informações atuais e de consistência. Documentação é o formato utilizado para a guarda de informações e reporting é o formato utilizado para comunicar a informação, planejando quais as informações que serão comunicadas e disponibilizar as informações às partes interessadas para diminuir a complexidade e amplitude dos projetos.

Cleland (2002, cap. 9) aponta quatro pontos fundamentais para a comunicação:

a) Sistemas de Informações gerencial dos projetos;

b) Comunicação em reuniões;

c) Comunicação em projetos abordando os processos de comunicação;

d) Negociações.

Embora estes pontos referem-se ao projeto Cleland (2002) preocupa-se também pelo papel do gerente enquanto líder (cap. 1) e quanto ao alinhamento dos projetos aos objetivos da organização (cap. 4). Enquanto que Valeriano aborda a questão da comunicação mais próxima ao âmbito do projeto em si, do cliente, e de manter um repositório de informações para consultas futuras.

Por outro lado a estrutura organizacional sempre é considerada como uma barreira comunicação gerando dinâmicas diferentes e conseqüentes distorções em na interpretação da comunicação conforme mostra a tabela 5.

Tabela 5 - Estruturas e formas de comunicação

\begin{tabular}{|c|c|c|}
\hline Estrutura & Característica & Impacto na Comunicação \\
\hline $\begin{array}{c}\text { Tradi- } \\
\text { cional }\end{array}$ & Formalização alta. Unidade de comando. & $\begin{array}{c}\text { Vertical. Segue a cadeia de autoridade com pontos } \\
\text { positivos: evita mal entendidos, melhor } \\
\text { coordenação; reforça autoridade do chefe. }\end{array}$ \\
\hline
\end{tabular}




\begin{tabular}{|c|c|c|}
\hline Estrutura & Característica & Impacto na Comunicação \\
\hline Inovativa & $\begin{array}{c}\text { Baixo nível de formalização. Formas avançadas de } \\
\text { departamentalização. Multiplicidade de comando. } \\
\text { Diversidade elevada; }\end{array}$ & $\begin{array}{l}\text { Vertical, horizontal e diagonal. Ponto positivo: } \\
\text { freqüência maior da comunicação. Pontos } \\
\text { negativos: sobrecarga pela freqüência da } \\
\text { comunicação; quanto maior a organização: maior } \\
\text { número de níveis que a comunicação tem que } \\
\text { passar; maior o tempo gasto para que a } \\
\text { comunicação seja completada. }\end{array}$ \\
\hline $\begin{array}{c}\text { Por } \\
\text { Projetos }\end{array}$ & $\begin{array}{c}\text { Fusão da Tradicional e Inovativa. Maior } \\
\text { diversificação de técnicos. Maior satisfação dos } \\
\text { técnicos pela visão de conjunto e interação. Maior } \\
\text { interação. Melhor atendimento a prazos. Melhor } \\
\text { atendimento ao cliente. Alivia a Alta } \\
\text { Administração que teria que fazer a integração. } \\
\text { Existência do Gerente do projeto como responsável } \\
\text { geral. Facilita e torna eficiente administrar os } \\
\text { projetos integrados. }\end{array}$ & $\begin{array}{l}\text { Comunicação vertical, horizontal e diagonal } \\
\text { facilitada por: maior integração; maior } \\
\text { colaboração; maior motivação; }\end{array}$ \\
\hline Matricial & $\begin{array}{l}\text { Gerente funcional e gerente de projeto com o } \\
\text { mesmo nível hierárquico e grau de autoridade; } \\
\text { Gerente de projeto não ocupa cargo funcional; }\end{array}$ & $\begin{array}{l}\text { Comunicação direta entre os mesmos níveis. } \\
\text { Comunicação direta entre níveis diferentes. } \\
\text { Comunicação entre dos especialistas com gerente } \\
\text { de projeto e gerente funcional }\end{array}$ \\
\hline
\end{tabular}

Fonte: Vasconcellos e Hamsley (2003)

Verifica-se que em todos os tipos de estrutura organizacional a existência de problemas e cabe ao líder conduzir os trabalhos percebendo as nuances e equilibrando as desvantagens.

O futuro das organizações será de luta na adaptação das estruturas e sistemas para a realização de projetos complexos e vitais. A equipe terá que atender os requisitos competitivos com velocidade, flexibilidade e autogerenciamento, e para isso precisará de pessoas com alta habilidade técnica e interpessoal e que se responsabilizem pela coordenação do fluxo do trabalho, para de fato gerar a confiança necessária para a execução do trabalho.

Sem liderança, treinamento, informação e recompensas necessárias como suporte, as organizações não poderão contar com equipes que atendam aos objetivos empresariais de hoje em dia. Confiança nas pessoas e trabalho duro não são suficientes nesse ambiente competitivo (GALBRAITH, 1995).

O processo de Comunicação é importante para assegurar que os objetivos estratégicos estejam alinhados com os projetos, dependendo decisivamente da contribuição do líder ou gerente de projeto com uma comunicação clara e precisa para que as ações planejadas sejam executadas com sucesso.

\section{Metodologia}

A pesquisa limitou-se à Comunicação no âmbito da estratégia de projetos numa organização mista ou paraestatal. Mais especificamente restringindo-se à comunicação dos objetivos estratégicos aos colaboradores que estejam envolvidos com projetos desta organização. Não foram abordados eventos comportamentais ou aspectos psicológicos ou sociais do líder, devido à complexidade 
teórica e de levantamento de dados a que este tema remeteria e por se tratar de estudo de caso (Yin, 2003 p.27). Para avaliar o problema proposto utilizou-se de estudo de caso tipo exploratório descritivo na avaliação dos processos de Comunicação e nas relações entre os aspectos levantados na fase de pesquisa bibliográfica e as respostas às questões levantadas no estudo. Levou-se em conta o instrumento de pesquisa, coleta de dados, elaboração e formulação das questões.

Com base na análise de conteúdo, (Oliveira, 2001) levantamento de material bibliográfico, estudo de campo (Gil, 2002), análise estatística, índices (Maravelakis, 2003) e indução analítica, a estratégia de análise foi realizada e ponderada.

\section{Resultados}

Dos Elementos observados, a "capacidade de planejamento e tradução dos objetivos estratégicos em metas" merece destaque, pois ele nos mostra o esforço necessário para se corrigir a direção da estratégia. Constatou-se que a empresa tem alto conhecimento sobre o que fazer, porém razoável conhecimento de para onde as tarefas/atividades estão levando a empresa. Outro aspecto é a dificuldade de avaliação dos resultados destas tarefas/atividades com planos e avaliação dos resultados não satisfatórios. Seria como colocar a questão da seguinte forma: "Se não se planeja para aonde vai, para que saber onde está?" - ou seja, como avaliar os resultados se não se conhece os objetivos?

A pesquisa aponta para uma empresa que parece conhecer muito bem os rumos do mercado e encaminha as atividades para o atendimento destas demandas com tendência forte, o que fortalece a capacidade de adequação às mudanças e melhorias. Entretanto a agilidade operacional constatada como alta pode estar sendo reduzida pela burocracia administrativa ou pela Média Gerência constatada como hierárquica, baixo empowement e de aspectos reguladores e legais.

A tabela 6 mostra o resumo dos resultados obtidos a partir do levantamento dos temas que influem na comunicação entre estratégia e projetos. A coluna "Resposta ao Problema da Comunicação" foi obtida a partir da análise individual e conjunta dos resultados estatísticos da pesquisa.

Tabela 6 - Resumo dos resultados

\begin{tabular}{|c|c|c|}
\hline Tema & Elementos observados & Resposta ao Problema da Comunicação \\
\hline $\begin{array}{c}\text { Contexto } \\
\text { Econômico }\end{array}$ & $\begin{array}{c}\text { Mudanças impostas pelo mercado, inovação e } \\
\text { tecnologia }\end{array}$ & $\begin{array}{c}\text { Razoável clareza de informações e do } \\
\text { detalhamento dos objetivos. Desempenho das } \\
\text { atividades alto com restrições quanto à } \\
\text { operacionalização. }\end{array}$ \\
\hline \multirow{2}{*}{$\begin{array}{c}\text { Adminis- } \\
\text { Tração }\end{array}$} & $\begin{array}{c}\text { Localização dos centros de decisão, e facilitação } \\
\text { da comunicação }\end{array}$ & $\begin{array}{c}\text { Centralização de tarefas na média gerência. } \\
\text { Facilidade de comunicação dificultada pela } \\
\text { hierarquia de decisão. }\end{array}$ \\
\cline { 2 - 3 } & $\begin{array}{c}\text { Abordagem sistêmica e conhecimento do } \\
\text { negócio, pessoas e disponibilizar informação. }\end{array}$ & $\begin{array}{c}\text { Razoável. Planeja menos que executa. Baixa } \\
\text { disponibilidade de recursos. Executa pela }\end{array}$ \\
\hline
\end{tabular}




\begin{tabular}{|c|c|c|}
\hline Tema & Elementos observados & Resposta ao Problema da Comunicação \\
\hline \multirow{6}{*}{$\begin{array}{l}\text { Adminis- } \\
\text { tração }\end{array}$} & & hierarquia? \\
\hline & $\begin{array}{l}\text { Modelo de gestão: mecanicista } x \text { orgânico e } \\
\text { modelo antigo } x \text { novo }\end{array}$ & $\begin{array}{c}\text { Mecanicista, hierárquico e antigo. Baixo } \\
\text { empowerment }\end{array}$ \\
\hline & $\begin{array}{l}\text { Planejamento, execução, recursos e tradução dos } \\
\text { objetivos em metas }\end{array}$ & $\begin{array}{c}\text { Razoável. Baixo Planejamento. Difícil avaliar } \\
\text { resultados. }\end{array}$ \\
\hline & Estruturas organizacionais & $\begin{array}{c}\text { Tradicional com viés matricial (funcional) e viés } \\
\text { hierárquico }\end{array}$ \\
\hline & Autoridade, responsabilidade e centralização & Alta e centralizada \\
\hline & Características entre setor público x privado & Burocrático, mais próxima ao tipo público \\
\hline \multirow{2}{*}{$\begin{array}{l}\text { Administração } \\
\text { Estratégica }\end{array}$} & Clareza e alinhamento dos objetivos estratégicos. & Razoável \\
\hline & Relação estratégia $\mathrm{x}$ estrutura & Estrutura funcional e de negócio único \\
\hline \multirow{4}{*}{$\begin{array}{l}\text { Comunicação } \\
\text { da informação } \\
\text { e o papel do } \\
\text { líder }\end{array}$} & Comunicação e compreensão das estratégias & Razoável, inclusive para projetos. \\
\hline & Barreiras na comunicação & $\begin{array}{c}\text { Barreiras comportamentais, estruturais regionais, } \\
\text { com informações razoáveis, porém pouco } \\
\text { adequadas }\end{array}$ \\
\hline & Comunicação vertical, horizontal e diagonal & $\begin{array}{c}\text { Verticalizada com dificuldade de apurar } \\
\text { resultados }\end{array}$ \\
\hline & Destreza e maestria do líder na comunicação & Baixa, dificultando implementação das ações \\
\hline
\end{tabular}

A questão 3 (figura 2), sobre os centros de decisão e sua relação com a estrutura hierárquica da empresa, foi a que mais chamou a atenção. Ela mostra que $63 \%$ dos respondentes aguardam pela distribuição de tarefas do nível Coordenação, 38\% acreditam que a definição de Metas e Objetivos vem da Diretoria e, embora tenham grande iniciativa para melhorias, a maioria dos respondentes (29 a 46\%) aguarda por orientações dadas pela média e alta administração.

Figura 2 - Localização dos centos de decisão

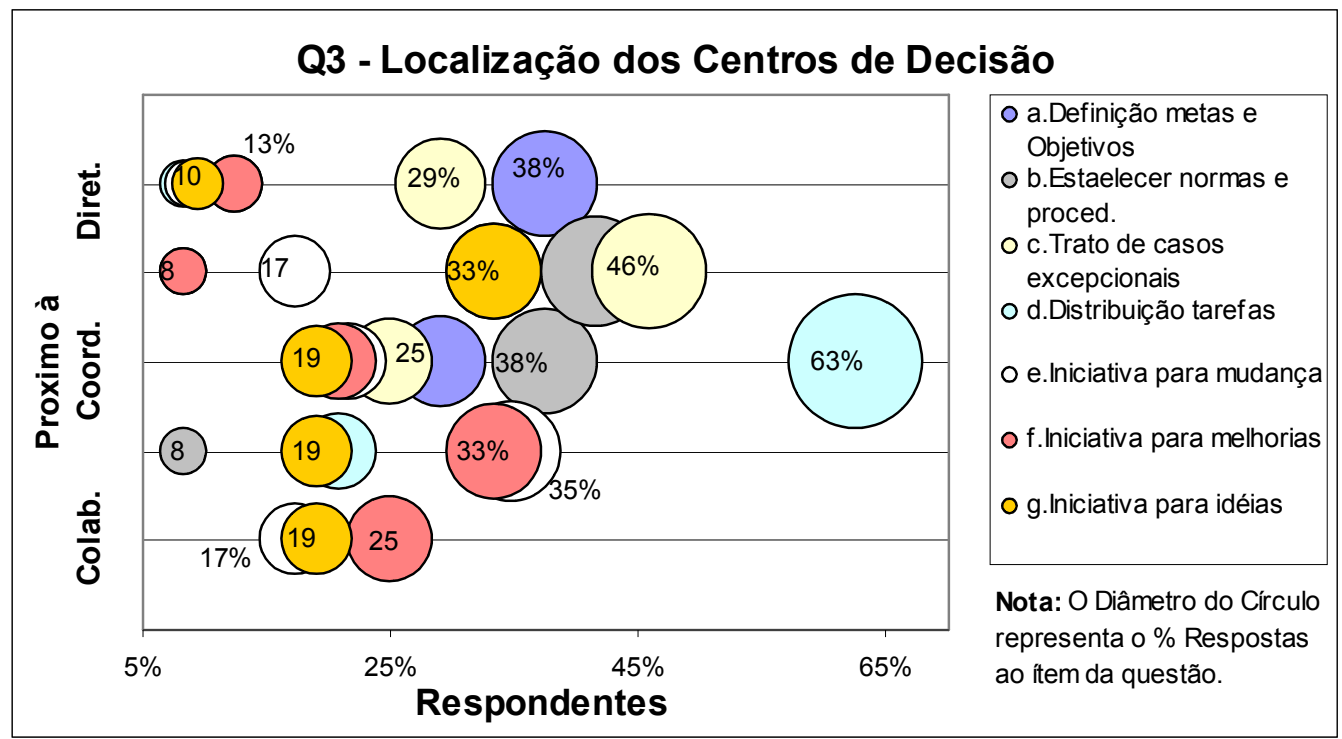

\section{Conclusão}


Pôde-se confirmar a existência de vários Elementos que se mostraram influenciadores nos vários aspectos da comunicação - desde a percepção de alto nível no contexto econômico até níveis mais baixos como a estratégia, estrutura organizacional e execução - responsáveis por informações a cerca do mercado, do planejamento estratégico, desdobramento nos projetos e consecução dos objetivos dos projetos. Os Elementos foram também considerados suficientemente apropriados para utilização no instrumento de pesquisa e para caracterizar os problemas da comunicação a partir da estratégia até execução tarefas.

Quanto à metodologia, técnicas e instrumentos utilizados, estes se mostraram apropriados ao levantamento das informações necessárias, aderentes aos propósitos da pesquisa e considerados satisfatórios para a obtenção dos dados, sua tabulação, análise e conclusões.

Os resultados mostraram-se relevantes e apropriados para utilização no ambiente organizacional, objeto de estudo. Como apontado na análise, pode-se dizer que apesar do esforço para uma maior sinergia e compartilhamento demonstrado pela Alta Administração, as respostas apontam para uma empresa com estrutura incompatível com a de projetos. A existência de hierarquias, baixo empowerment, concentração de informações e tarefas na Média Gerência, além de dificuldade na avaliação de resultados reflete o baixo nível de planejamento das atividades e recursos e são direções confirmadas nesta pesquisa.

As disfunções mostradas na tabela 6 constituem, ainda, um guia consistente para proposições de melhorias da comunicação na ambiência de projetos da organização respondendo à pergunta inicial e, embora não limitadas a estas, estas melhorias são brevemente listadas a seguir.

\section{Sugestões}

A pesquisa realizada contribuiu para levantar disfunções da comunicação e dentre as disfunções observadas às seguintes sugestões de melhoria foram apresentadas:

- Promover maior interação entre níveis readequando-os para um estrutura por projetos;

- Criar um comitê para definir e alinhar projetos essenciais ao atingimento dos objetivos estratégicos com critérios transparentes, entendidos e aceitos por todos;

- Criar escritório de projeto para reivindicar e diligenciar informações sobre projetos em execução e comunicar a organização sobre o andamento destes;

- Constituir formas de melhorar o planejamento e utilização de recursos;

- Continuar o programa de desenvolvimento de gerentes de projetos;

- Instituir e fortalecer o empowerment;

- Readequar a Estrutura Organizacional num modelo mais próximo a "Negócios Relacionados", consistente com as características da empresa; 
- Estudar as regulações, procedimentos e diretrizes, readequando-as de acordo com a estratégia adotada e dando significado na relação causa $x$ efeito para modelo de gestão, estrutura organizacional e forma de comunicação;

- Ampliar a horizontalização diminuindo os efeitos dos centros de decisão;

- Reforçar papel dos dispositivos tecnológicos na comunicação;

- Aumentar clareza dos objetivos dando maior coerência na avaliação de resultados;

- Criar programa para desenvolvimento de líderes.

Embora o resultado aponte para estas ações de melhoria, outros trabalhos e estudos devem ser realizados e explorados a partir desta pesquisa inclusive aqueles ligados à área Jurídica e assuntos reguladores e assim agregar mais valor ao resultado pretendido que contribuirá para uma maior profissionalização da organização.

\begin{abstract}
The speed of transformation in which the world has passed brought a new organizational paradigm lead and pressured by the vectors social, economic, environmental and technological, imposing a innovative and dynamic face in the strategic formularization capacity and in the synchronized and intelligent connection of the activities. This reorganization process, imposed by the age of the knowledge economy, strengthens the necessity of new models of management and adjusted projects with bigger effectiveness toward to the strategic objectives fulfillness. To deploy and execute the strategic planning, its associated projects and to lead people, those must be provided by a systemized, articulated and coherent process of communication. The objective of this work was to evaluate the processes of communication between strategic objectives and the projects, from the previous context, in an organization that works by projects. A private company regulated by government (parastatal) was chosen where the answers of a survey, sent to collaborators tied to projects based and supported by the searched literature, was analysed.
\end{abstract}

Key words: Communication; Project Management; Portfolio Management; Parastatal.

\title{
7. Referências Bibliográficas
}

ARGYRIS, C.; BARTOLOMÉ, F.; ROGERS, C. Comunicação eficaz na Empresa. Rio de Janeiro: HBR-Campus, 1999.

BASTOS, V. L. \& SILVA, M. L. F. Para entender as economias do terceiro mundo. Brasília: UnB, 1995.

BOYETT, J. H. e BOYETT, J. O Guia dos Gurus - os melhores conceitos e praticas de negócios. Rio de Janeiro: Campos, 1999.

BRASIL. Decreto Lei no 494 de 10.01.1962. Aprova o regulamento do Serviço Nacional de Aprendizagem Industrial. Disponível em: http://www.planalto.gov.br/CCIVIL_03/decreto/1950-1969/ D0494.htm. Acesso em 31.01.2005.

BRASIL. Decreto Lei $\mathbf{n}^{\mathbf{0}} \mathbf{5 7 . 3 7 5}$ de 02.12.1965. Aprova o regulamento do Serviço Social da Indústria (SESI). Disponível em https://www.planalto.gov.br/ccivil_03/decreto/1950-1969/D57375.htm. Acesso em 31.01.2005.

CLELAND, D. I. e IRELAND, L. R. Gerência de projetos. Rio de Janeiro: Reichmann \& Affonso, 2002.

DINSMORE, P.; AMARAL, R.; SIQUEIRA, C.A. Gerência por Projetos na Administração Pública. Rio de Janeiro: Dinsmore Associates e CEBELA, 1998. 
GAlBRAith, J. R.; LAWLER III, E. E. Organizando Para Competir no Futuro. São Paulo: Makron Books, 1995

GIL, A. C. Como elaborar Projetos de Pesquisa. São Paulo: Atlas, 2002.

KARLÖF, B. Conceitos Básicos de Administração - um guia conciso. Rio de Janeiro: Rocco, 1999.

MARTIN, J. A Grande Transição. São Paulo: Futura, 1996.

MARAVELAKIS, P. E.; et al. The Use of Indices in Surveys. Department of Statistics, Athens University of Economics and Business, Greece. Printed in the Netherlands, Kluwer Academic Publishers, 2003.

MaXimianO, A. C.A. Teoria Geral da Administração. São Paulo: Atlas, 2000.

MINTZBERG, H.; AHLSTRAND, B.; LAMPEL, J. Safári de Estratégia. Porto Alegre: Bookman, 2000.

OLIVEIRA, S. L. Tratado de Metodologia Científica. São Paulo: Pioneira, 2001.

PIMENTA, R. B. XXIII Simpósio de Gestão da Inovação Tecnológica, 2004. Comunicação Eficaz: Competência Gerencial Estratégica na Condução de Equipes de Projetos.

PORTER, M. E. Competição - Estratégias Competitivas Essenciais. 3e. Rio de Janeiro: Campus, 1999.

VALERIANO, D. L. Gerência em Projetos. São Paulo: Makron/CTA, 1998.

VASCONCELLOS, E. e HEMSLEY, J. R. Estruturas das Organizações - estruturas tradicionais, estruturas para inovação, estruturas matriciais. São Paulo: Thomsom Pioneira, 4e, 2003.

YIN, Robert K. Estudo de Caso - Planejamento e Método. Porto Alegre: Bookman. 2002.

\section{Autores:}

Nome: Jorge Luciano Gil Kolotelo

Filiação institucional: Universidade Tecnológica Federal do Paraná - UTFPR

Departamento: Programa de Pós-Graduação em Engenharia de Produção

Função: Mestrando em Engenharia de Produção

Endereço: Rua Itupava, 509 - Ap. 56 - Alto XV - Curitiba - PR - CEP 80040-000

e-mail: jlkolotelo@gmail.com

Nome: Hélio Gomes de Carvalho

Filiação institucional: Universidade Tecnológica Federal do Paraná - UTFPR

Departamento: Programa de Pós-Graduação em Engenharia de Produção

Função: Professor Permanente

Endereço: Av. Monteiro Lobato, Km 04 - Ponta Grossa - PR- CEP: 84.016-210

Fone: (42) 3220- 4805

e-mail:helio@utfpr.edu.br 